\title{
Wading Through Misery, Hope and Beauty in Caring For Cancer Patients: Experiences of Oncology Nurses
}

\author{
Belza, Mercedes A. MAN, Phd., Dancil, Veronica T. MSN, Lauro, Jocelyn P. MAN, MaEd. (u)* \\ Far Eastern University, Nicanor Reyes St, Sampaloc, Manila, 1008 Metro Manila, Philippines \\ *Corresponding Author \\ Jocelyn P. Lauro
}

Article History

Received: 30.08.2019

Accepted: 06.09.2019

Published: 30.09 .2019

\begin{abstract}
Nurses are often engaged in providing care for patients who are diagnosed with terminal illness and are faced with the process of dying. Working with these patients and families can be emotionally demanding and challenging. Nurses ought to meet the challenge of developing and rendering effective interventions for cancer patients, focusing predominantly on health promotion, end-oflife care, and above all, the four domains of health-related quality of life: physical, psychological, emotional and spiritual functioning. Health-related Quality of Life (HRQoL) interventions can empower patients to practice health behaviors and facilitate them to be selfdirected in their care; thereby contributing substantially to their quality of life. This study aimed to describe and understand the 'lived' experiences of oncology nurses in providing health-related quality of life interventions among cancer patients. The study was conducted using descriptive phenomenological method and data was generated through one-on-one audio-recorded interview with ten oncology nurses Colaizzi's [1] procedural interpretation of the phenomenological method of inquiry was used for data coding and identifying themes. Methods to ensure trustworthiness of the findings were implemented. Three themes with 14 sub-themes were identified. Results of the study showed that health-related quality of life interventions were essential in nursing care among cancer patients. It was suggested that the manner in which cancer patients' quality of life improves through HRQLL interventions should be further studied. In addition, it may be of value for nursing leaders to provide specified training programs for oncology nurses working on issues relevant to the HRQoL intervention skills.
\end{abstract}

Keywords: Oncology Nurses, Cancer Patients, Health-related Quality of Life, Health-related Quality of Life Interventions.

\section{INTRODUCTION}

Health-related Quality of Life (HRQoL) is the individuals' happiness or satisfaction in relation to their physical, psychological, emotional and spiritual functioning. These are concerned primarily with factors that fall under the purview of healthcare providers and healthcare systems. The notion of HRQoL and its determinants were developed to encompass those facets of over-all quality of life that can be clearly shown to affect health, either physical or mental. The HRQoL of people suffering from cancer was a significant concern to the healthcare system and healthcare professionals, particularly nurses who were providing direct care to these patients.

American Cancer Society [2] disclosed that cancer amounts to a massive burden on society, both in more and less economically developed countries. The incidence of cancer is increasing because of the growth and aging of the population, as well as an increasing prevalence of established risk factors, such as smoking, overweight, physical inactivity, and changing reproductive patterns associated with urbanization and economic development. According to Ferlay et al., [3], GLOBOCAN estimates, about 14.1 million new cancer cases and 8.2 million deaths occurred in 2012 worldwide. Over the years, the burden has shifted to less developed countries, which currently account for $57 \%$ of cases and $65 \%$ of cancer deaths worldwide.

It should be the goal of every oncology nurses to aid patients to manage the issues associated to their cancer experience. To achieve this requires building a rapport with the patient and therapeutic use of self. By becoming part of the patient's universe, the nurse shares the burden of agony thru empathy, caring, and compassion [4]. Nurse's conscious and unconscious feelings are part of the relationship and enter into exchanges with patients [5]. Ultimately, nurses' ability to communicate will influence the success of providing HRQoL interventions thru therapeutic communication.

Copyright @ 2019: This is an open-access article distributed under the terms of the Creative Commons Attribution license which permits unrestricted use, distribution, and reproduction in any medium for non commercial use (NonCommercial, or CC-BY-NC) provided the original author and source are credited. 
Since nurses are the most essential part of the caring process and several discussions on the role of physical, emotional, psychological and spiritual care in the prognosis of cancer patients crop up without any tangible studies conducted, a question was posed for oncology nurses: What is it like to render HRQol interventions to Cancer patients? To deal with this inquiry, we conducted a qualitative study to elucidate and clarify the depth of oncology nurses' experiences in providing HRQLL interventions among cancer patients.

\section{Methodology}

This study made use of descriptive phenomenological design to accurately describe the 'lived' experiences of oncology nurses in providing health-related quality of life interventions among cancer patients. According to Speziale and Carpenter [6], the goal of descriptive phenomenological research is to describe a particular phenomenon or the appearance of things, as lived experiences.

Colaizzi's [1] method of data analysis was used to provide assistance in extracting, organizing, and analyzing the narrative dataset. Applying Colaizzi's strategy in descriptive phenomenology was to elicit an exhaustive description about the phenomenon regarding oncology nurses' experiences in taking care of cancer patients. To begin with, we transcribe, read, re-read, and analyze a description of each informant participating in the study to acquire full understanding of the data. Then we extracted statements with importance to the research question, such as descriptions of how an oncology nurse feels about in providing health-related quality of life interventions among cancer patients. To reflect the research data precisely, the important statements was made through quotations from the informants. To analyze the important statements, we commenced to articulate what the statements denote and generate themes from the meanings. Then we clustered related themes together and organized them into sub-themes. In this study, we obtained three themes and 14 sub-themes. Lastly, we incorporated the results into a complete description of the topic and consulted to each informant to validate the results.

Credibility and conformability was established through member checking. The report of the analyses was given to the informants in order to get guarantee that we described their real world in themes and extracted sub-themes.

\section{Participants of the Study}

Nurse informants were recruited using purposive sampling based on the following criteria: (1) currently employed as oncology nurse; (2) at least twenty-five (25) years of age; (3) with at least three (3) year experience as oncology nurse; (4) male or female Filipino nurses; (5) working in a government hospital in Pasig City; and (6) willing to share their experiences. Eight female and two male nurses participated in the study and completed a demographic form prior to the interviews. The ages of the informants ranged from 28 to 57 and their maximum time of clinical experience as oncology nurse was 10 years and the minimum was 3 years.

\section{Data Collection and Data Analysis}

Data were gathered through in-depth interviews with each informant from February to May 2015. The interviews were conducted face-to-face at a pre-arranged dates and time and lasted approximately 30-60 minutes. The interviews were continued until no new theme emerged. Data saturation was obtained after all the interviews. They were tape-recorded and transcribed verbatim. The researcher approached the informants with a very broad question that contemplated on the description of the lived experiences in providing HRQoL interventions. The main question asked was "Can you tell me what is it like to be an oncology nurse providing health-related quality of life interventions among cancer patients?" At first the informants were requested to share their stories but in the subsequent questions, the researchers asked probing questions that were in direct response to the informants' descriptions to arrive at a deeper level of understanding, to reflect and to validate. It was through this intersubjective interview that the informants and the researchers built up the essential description of the lived experiences in providing HRQoL interventions among cancer patients.

\section{Ethical Considerations}

This study was subjected to the ethical review of the University Research Center - Ethics Board Committee of Far Eastern University - Institute of Nursing. Hospital and informed consent from each informant was sought prior to the interviews. This study has been guided by the following ethical principles: (1) autonomy, right to know and to withdraw were respected by providing the informants with all information pertinent to the study and by making them understand that their participation was completely voluntary and had the right to withdraw any time; (2) non-maleficence was observed by discussing to them the risks of discomforts; and (3) privacy and confidentiality were guaranteed by storing all data in a secured place and all information acquired from the informants was treated non-identifiable and confidential manner.

\section{FINDINGS}

The lived experiences of oncology nurses in providing HRQoL interventions among cancer patients was formulated in three themes and 14 sub-themes. The first theme is "Drowning the demons of misery", which includes five sub-themes: (1) Downcasted from trying to be stronger than they feel, (2) This is not how my story will end, (3) The thing about pain, you'll never know how much it hurts (4) No man is rich enough to buy back his health, and (5) Acceptance is the road to all change. The second theme is "When there's life, there's hope", which includes five sub-themes: (1) Building bridges beyond walls, (2) From the heart through the hands, (3) Worry ends when faith in God begins, (4) Seeing life sideways, and (5) We rise by lifting others. The third theme is "Finding beauty in 
the ugliest days" which includes four sub-themes: (1) The more you care the more you have to lose, (2) Anticipate the difficult by managing the easy, (3) When the pressure is too much to handle, and (4) Finding the calm in the chaos.

\section{Drowning the Demons of Misery}

All the informants were fretful to the reality that they need to consider and connect in patients' feelings of existential misery to avoid it from being linked with helplessness and hopelessness.

\section{Downcasted from Trying To Be Stronger Than They Feel}

Several informants perceived that emotional care of the terminally ill cancer patients is important to address their needs. Some of them acknowledged the fact that at least a quarter of patients with advanced cancer have a symptom of depression. For instance, N8F said very graphically: "Their emotions weren't stable. They try to be okay but sometimes they remember something and there's a shift. They get sad and then they cry."

One informant described depression in cancer patients as highly ubiquitous and can significantly affect their probability of survival. According to N1F: "Depressed patients are really those that go through chemo. You'll notice differences whenever they come back and the prognosis is bleak."

Another informant (N1F) added that knowledge about depression, the recognition of symptoms like 'appropriate sadness' due to the patient's trying to conquer fear of death and initiation of treatment is essential for optimum cancer care: "Listen to the depressed. They speak whatever it is on their minds. But even when you don't hear it, you can see in their actual appearance how depressed they are. So that's what you really need to be able to see, since the cancer could worsen because of it."

\section{This Is Not How My Story Will End}

Many times during their treatment and recovery, N2F noted that people with cancer were worried and fearful on how their different life situations will end. Fear of treatment, doctors' visits, and tests caused trepidation - the feeling that something bad is going to happen: "They were scared that when they stop doing chemo, their illness will worsen or, that they will die."

Similarly, N5F added that cancer patients are afraid of uncontrolled pain, thinking of what happens after death, including what might happen to their loved ones: "Whenever they see their children visiting, they end up crying. They don't speak about the pain they feel, but I interpret it as these people not yet wanting to leave their kids unstable."

\section{The Thing about Pain, You'll Never Know How Much It Hurts}

One of the focal point of nursing care among cancer patients is pain. One informant said that pain is permanent or frequent for patients with advanced cancer and most of them who die as a result of cancer suffer from pain in the final phase of life. Here is N6F: "Stage 3 or 4 patients can be demanding as they are in extreme pain. You can't really tell what it is, and even if you have a high threshold of pain, it's different with then. Tramadol isn't enough; only morphine will relieve their pain."

Informants disclosed that nurse's role in terms of pain management was of great importance. N3F stated that nurses should make an assessment of patients' problems and needs, to suggest and conduct health teaching regarding pain and some reliefs, initiate and perform interventions for relief of pain and other symptoms while preventing negative side-effects of medication.

\section{No One Is Rich Enough To Buy Back one's Health}

Life changes with cancer. Informants spoke about loss of income as one of the greatest financial implications for people diagnosed with cancer. N2F stated: "One of their main concerns is finance, as treatment is expensive." N8F added: "Even those who are well off, their resources will really be drained as the medications used are really expensive." Another said, N1F: "Cancer really calls for a lot of money, as it's a lifetime of treatment. Even when you wish to become better, it comes back, and even spreads."

Some informants were able to communicate that those in employment at the time of diagnosis experience loss of income. Some have to use savings and some borrow money from financial institutions, friends, family, or employers. Monetary repercussions were expressed by N3F: "Some will tell you they really have no money anymore, their house is pledged, they've borrowed so much money already."

As consequence, patients want to seek financial help soon after being diagnosed with cancer because bills and debt quickly. Oncology social workers, case managers, doctors, and nurses can help or provide referrals to support services and financial resources. For instance, N8F revealed: "When someone opens up about financial problems, we refer them to a social worker, such as PCSO to help them. There are also government agencies. We give them options; we help them by referring them to agencies that can help." 


\section{Acceptance Is the Road to All Change}

Patients have varied ways of copings with a cancer diagnosis. One informant, N6F stated: "No matter how you try to make them happy, especially if they are in the denial stage, it really won't do anything. Other patients are easier in accepting, depending on their own coping mechanism." Another informant described her experience that the response of cancer patients to a poor prognosis is ranging from shock and denial through anger, depression and finally acceptance.

Most people can handle the news that they have cancer, but each person needs time to adjust and figure out what the diagnosis means to them while some coping strategies may also influence the prognosis.

Several informants asserted that patients, whose strategies focus on accepting the condition, or on seeking solutions to problems, show a better subsequent adjustment. N8F adds that: "When they've accepted that this is now their quality of life, their days are prolonged. But of course if they're on stage 4, it's really terminal already. But they still enjoy life better when they've accepted their condition."

\section{When there's life, there's hope}

All informants were vastly encouraged in caring for cancer patients holistically, with emphasis on the physical, psychological, emotional, and spiritual aspects of care.

\section{Building Bridges beyond Walls}

Many informants described how trying to see things from a patient's viewpoint and empathizing with their emotions make them feel important. For instance, N3F stated: "Don't hesitate striking a conversation with the patient, even when they get irritable sometimes, they're always in pain. But once you show concern and compassion, you make them feel important even if it's just for five minutes."

Learning to reflect the patient's feelings in a deeper meaning makes them feel heard and understood. Nurses don't analyze, interpret, judge, or give advice. One informant expressed his understanding that whenever patients feel they are being heard, they are less anxious, complain less about their nurses, and are more likely to comply with their treatment plan by saying.

The actions and practical competence that the nurse demonstrated based on the standard of care allows the patient to trust them. As one informant said, N8F: "Once the patient opens up or a relative, it makes you happy because you showed them you're ready to listen."

\section{From The Heart through the Hands}

Patients receive messages each time they are "touched". As N4F stated that cancer patients can sense and feel the uneasiness, nervousness, tension, anxiety and also carelessness being conveyed, through the interpretation of the body language of nurses and closed ones but also in the way they are touched while being cared for.

While the words accompanying the manual interventions may be chosen to disguise any complexity or frustration on the part of the nurses, the sensory input through the hands often converse another truth, which commonly increases the patients' feeling of dependency. N8F states: "It's important for the patient you stroke them while saying things like, "ma'am, it will be okay," by doing that you make them feel that you're there for them."

Touch may be the finest way to convey empathy, understanding or reassurance, and will often outweigh words. Touch makes a significant difference for patients whose pain is difficult to control as stated by N3F: "The pain might be unbearable, but with a simple touch, it's like they feel relief, they feel calmer."

\section{Worry Ends When Faith in God Begins}

Many informants described how people's exposure to stressful events and incurable diseases like cancer made them turn to religion and spirituality. For instance, one informant, N10M stated: "So far, I haven't had experience yet where they blame God. In fact, most of them become closer to God. And when they get closer to him, they accept their condition."

And yet, despite professing a belief that spiritual care is an important component of health care because people tend to hold on to God as their last and final resort, nurses do not routinely and consistently provide spiritual care to their patients. N2F says, "The spiritual aspect of care, though important, is not really our priority. Sometimes it is, sometimes not, as nurses don't have that much time, and also, because they all have different beliefs so there's no single approach."

\section{Seeing Life Sideways}

Humor helps ease the pain. It shows the human side of the health care team and generally helps everyone cope. One of the informants stated that when humor is used sensitively, respecting the gravity of the situation, it can build the connection among the caregiver, patient, and family: "Whenever I provide care, no matter how difficult it is, I just joke with them. Sometimes there are young 
lads doing chemo and though I know they are very young, I joke, "Tay, you're still young?" "Yeah," "Me too." It's really all you can do for them to ease their difficulty" (N4F). vibes."

Another informant added: "You should always be smiling. As their nurse, when they see you smiling, it brings them positive

Being a patient advocate, nurses' uses therapeutic interventions such as storytelling that provide patients and their families a venue to express feelings and describe experiences when faced with devastating situations such as a diagnosis of cancer. For instance, N1F noted: "You share with them the experiences you've had caring for others, but you don't compare them. You just share those that will motivate and inspire them."

\section{We Rise By Lifting Others}

Nurses are faced with the difficult challenge of being positive and supporting patients in trying to be optimistic. As stated by one of the informants: "The role of nurses is important in keeping the patients optimistic. When a person becomes ill, it's not just their organs. Nurses can change their minds, for example, nurses can explain to them and then make them feel that they are understood, no matter how horrible they feel, they won't have to feel alone" (N1F).

Informants spoke on the significance of allowing patients to express their negative feelings about their illness and treatment when they feel they need to, in order to reinforce positive disposition. On the other hand, nurses also encourage the patient to regain control of their lives, experience hope and reconciliation through the development of their potential even in difficult times. N5F noted: "When you give medication to depressed patients and they say, "Later", you say "You need to take it now." You watch them and encourage them to take it on time."

\section{Finding Beauty in the Ugliest Days}

Informants' repeated exposure to trauma can be a regular stressor for them as they witness their patients' physical, psychological, emotional, and spiritual suffering everyday.

\section{The More You Care the More You Have To Lose}

Nurses who have developed strong interpersonal relationships with patients often share the suffering experienced by the relatives of a cancer patient, and may experience a similar sense of bereavement when the patient dies. For instance, N1F stated: "When you see chemo's side effects, you really feel for the patient. You develop a bond with them; they don't just do chemo once, it happens twice, thrice, even more. As a nurse, you know you have emotions, and you feel for them, but there's nothing you can do but serve them."

One informant noted that nurses tend to get to know the cancer patients, their families, even their friends because they keep on returning in the institution for their treatment sessions. And because they get know them so well, in such an intense and intimate setting, they end up caring about them. N6F added, "I had a patient I took care for a long time and when he died, I was devastated. I got to know their family, and they were all so kind and so close. So I felt like I was part of the family, so when the death came, I was also devastated."

Many informants described what it means to be an oncology nurse, a no-win situation where compassion routinely gets hijacked by grief. When a cancer patient died in the hospital, the person caring for them in their last days, hours, and minutes is the nurse because they are the ones who are always there. N8F added: "One of my patients who died, I was called to his bedside and I was holding his hand for a few minutes with his family. But I left because I knew I was going to cry. I didn't want her family to cry and for them to see me crying, too, as I was the caregiver, so I thought they shouldn't see me cry."

\section{Anticipate the Difficult By Managing the Easy}

A nurse's road to fulfillment is not always dominated by grateful and gentle patients. One informant noted that she can't call herself a nurse unless she accepts the fact that dealing with grumpy, over demanding, and ill-tempered patients every once in a while is quite inevitable in one's nursing career: N8F added: "I had a patient with breast cancer once and she was the type that was particularly snobbish. As a nurse, there's nothing you can do except accept her attitude towards you and just understand."

Many informants emphasized that responding to cancer patients' anger requires empathy and a willingness to understand the meanings of their anger that might allow the patient to be accountable for their attitude to their illness. Another informant added: "It's challenging, as you encounter different attitudes. But you need to be really patient, because we don't know how it feels to have cancer. Later on, they also smile and greet you" (N10M).

\section{When the Pressure Is Too Much To Handle}

One informant described nurses as often too busy to deliver all care duties; most significantly to oncology patients, because of the absence of standards for nurse-patient ratio. For instance, N1F stated: "The ratio for oncology nurse to patient is low. Cancer 
patients have so many questions and doubts, which you must answer accurately. They need to hear sincerity in your answer, sometimes, you're in a hurry. That's the challenge. Because of the ratio, it's difficult to handle well when they ask you to explain."

Health-related quality of life interventions are frequently being left undone as a result of caring for several patients alongside its non-caring tasks. As described by one informant, nurses are being forced to rush care because they do not have enough time to properly look after their patient. N2F says, "Sometimes it gets really difficult to handle them all at once, for example, we have four chemo patients and just one nursing attendant. So you can't really give them the quality of interventions in your eight hour duty, you're always rushing everything. And other than them, you have other patients and other errands."

\section{Finding the Calm in the Chaos}

Nurses were asked to be doing more and more with less and less. Keeping a cool head on their shoulders and having compassion is clearly something that helps. For instance, one informant stated that sometimes it can be very difficult for the nurses to maintain a calm demeanor when things get out of hand. This is particularly true when patients are displaying challenging behavior because patient care is central to the job of a nurse.

Many informants accepted the importance of patience in their situation. Whether it's a lack of sleep, a doctor being shorttempered or a very demanding patient, nurses can diminish their stress level by refining their capacity to be patient. For instance, an informant revealed: "In my experience as an oncology nurse, patience is really an important part in my role in dealing with people and colleagues. Especially those who are just newly diagnosed, they are more snobbish, so you don't show the same bad attitude to them. You just try to understand them better, as they are really going through something difficult. Even doctors or colleagues who are in a foul mood, you try to be patient around them, because you know you are all tired and others are on a 24 hour duty." (N8F)

\section{Discussions}

The analysis revealed that the nurses interviewed in this study developed a string of responses as they were providing $\mathrm{HRQoL}$ interventions among cancer patients. They accentuated various and comprehensive challenges in order to provide HRQoL interventions in their daily professional caregiving task. These experiences helped the nurses to reflect on the magnitude of HRQDL interventions and also their behaviors towards cancer care, regardless of their self-limitation and naivety in HRQL interventions for cancer patients.

The current study formed numerous results that highlighted the experiences of cancer patients. Firstly, depression and anxiety are common among people diagnosed with cancer. Stress is often a trigger for depression and anxiety, and cancer is one of the most stressful events that a person may experience. These conditions may interfere with cancer treatment. The patients with untreated depression or anxiety may be less likely to take his cancer treatment medication and continue good health habits because of fatigue or lack of motivation. They may also withdraw from family or other social support systems, which means they will not ask for the needed emotional and financial support to cope with cancer. This in turn may result in increasing stress and feelings of despair [7].

Besides, cancer patients have concerns about an uncertain future, horrendous pain, the potential for treatment failure, the cancer spreading, the possibility of death, financial insufficiency, and whether they can admit to themselves that they are critically ill or not. Cancer patients suffer extensive misery from diagnosis to treatment and beyond. Since cancer affects not only the physical but also the psychological, emotional and spiritual status of the patient [8] in countless ways, there is no single trail taken by all cancer patients. The misery is shared between the patient and healthcare professionals, and nurses can provide both care and support to patients throughout their desolation [9]. Thus, oncology nurses who are comfortable with listening and discussing existentially related concerns may be in a better position to promote the patient's physical, psychological, emotional and spiritual adaptation. With a nurse's help, if a patient can resolve the miseries that impact quality of life during treatment, it may greatly improve their outlook. It is difficult for patients to focus on learning about anti-cancer treatment if they are overwhelmed with anxiety and distressing thoughts [10].

In the present study, oncology nurses empower the patients to establish hope and reconciliation thru rapport and communication, touch intervention, enhancing faith, inserting humor during interactions, and helping the patients develop a positive outlook in life despite their condition. Open communication is the cornerstone of rapport between nurse and patient. The patient wants to know what is going on and will appreciate it when the nurse keeps them informed [11]. This help relieve patients' stress and then they can begin focusing on cultivating a healthy and positive nurse/patient relationship that will lead to increased chances of a speedier recovery [12]. Nursing touch is powerful and can be an excellent way to bring the patients' stress level down a notch or two. Based on a research, an affirmation can be made regarding the use of therapeutic touch as a non-invasive intervention for improving the health status in patients with cancer [13]. It can relieve their pain, anxiety and stress, and improve their quality of life [14].

Nurses in the present study talked about humor as one of the efficient approach to establish hope among cancer patients. It has been suggested that the use of humor permits patients to psychologically distance themselves from their own death, while still allowing an acknowledgment of their terminal condition, thus helping to limit their psychological level of awareness of their condition and being an acceptable way to deny reality [15]. Likewise, oncology nurses in this study aid patients in developing optimism 
that could help them achieve a good prognosis. According to International Association for the Study of Lung Cancer [16], researchers focused on lung cancer patients and discovered that those who exhibited an optimistic disposition experienced more favorable outcomes than those with a pessimistic disposition. Larsson, Hedelin and Athlin [17] reported that the encouragement and support given by the nurses motivated the patients to go on. The oncology nurses assist the patients to regain some balance in their daily lives by creating a new life as a final phase in the process of cancer survivorship. Nurses encourage patients because they believe that patients can use their strengths even in difficult times [18].

Failure to give attention on the spiritual aspect of HRQoL interventions to cancer patients is evident in this study. Cancer patients draw strength from their faith when faced with the illness that has overwhelmed them physically and emotionally. Hope is particularly important for those suffering with cancer. Researchers have found a strong link between religious beliefs and hope. Hope enables people to actively cope with difficult and uncontrollable life situations. Patients with a strong sense of hope report a high quality of life, and hopefulness is linked to better adjustment by radiation therapy patients being treated for cancer. Robust hope can give a patient strength and courage to face the stress of illness and treatment, while hopelessness brings passivity and resignation [19].

Oncology nurses have been personally affected by their attachment in caring for cancer patients. They reported emotional grief when having a dying cancer patient during their shifts and experiencing the divergence between professional duty of providing quality care and personal inadequacy, which prohibited them from achieving this. Due to the length and intensity of their interactions, oncology nurses can be at risk of becoming overly involved with patients and their families; this 'unhealthy' empathy leads to the blurring of professional boundaries and constitutes a major stressor in hospice nursing [20]. Oncology nurses face the challenge of working intensively with seriously-ill patients and their families at highly emotional and stressful times in their lives [21, 22]. Constant exposure to grief and to the experience of multiple deaths may lead to 'grief overload' [23]. Healthcare professionals who have developed strong interpersonal relationships with patients often share the suffering experienced by the relatives of a dying patient, and may experience a similar sense of bereavement when the patient dies [24].

In addition, certain nurses in the study experience exhaustion for having to deal with difficult patients together with their excessive work load. However, they manage to remain unruffled regardless of the extreme demands on them. Becoming a nurse is still very rewarding, because it's such an important job. Yet in a high-stakes environment like a hospital, sometimes it can be difficult to maintain a calm demeanor when things get out of hand. This is particularly true when a patient is displaying challenging behavior or when the heavy workload is too much to handle [25. Nurses must have a huge internal storage house of patience in order to keep their tolerance [26].

\section{CONCLUSIONS}

Health-related quality of life interventions was verified to be an essential element of nursing care among cancer patients. Oncology nurses should consistently provide therapeutic interventions for physical, emotional, psychological and spiritual aspects that promote the improvement of health conditions of patients with cancer and their QoL [27]. The findings of the present study provide insights into recognizing the full significance of $\mathrm{HRQoL}$ interventions among cancer patients wherein oncology nurses encountered serious challenges when delivering HRQoL interventions because of attachment, difficult patients, work overload and temper. Oncology nurses can take an active role in enhancing the consistency of providing HRQoL interventions to patients with diverse health conditions. How the cancer patients' quality of life improves through HRQoL interventions should be further studied. In addition, it may be of value for nursing leaders to provide specified training programs for oncology nurses working on issues relevant to the HRQoL intervention skills.

\section{REFERENCES}

1. Colaizzi, P. (1978). Psychological research as the phenomenologist views it. In: R. Valle \& M. King (Eds.), Existential phenomenological alternatives for psychology (pp. 48-71). Oxford: Oxford University Press.

2. American Cancer Society (2015, June 28). Anxiety, fear, and depression. Retrieved from http://www.cancer.org/treatment/treatmentsandsideeffects/emotionalsideeffects/anxietyfearanddepression/anxiety-fear-anddepression-depression

3. Ferlay, J., Soerjomataram, I., Ervik, M., Dikshit, R., Eser, S., Mathers, C., Rebelo, M., Parkin, D., Forman, D., \& Bray, F. (2013). GLOBOCAN 2012 v1.0, Cancer Incidence and Mortality Worldwide: IARC Cancer Base No. 11. Lyon, France: International Agency for Research on Cancer.

4. King, P., \& Jordan-Welch, M. (2003). Nurse-assisted suicide: Not an answer in end-of-life care. Issues on Mental Health Nursing, 24(1), 45-57. https://www.ncbi.nlm.nih.gov/pubmed/12735074

5. Lancely, A. (2001). The impact of cancer on health professionals. In: T. Corner \& C. Barley (Eds.), Cancer nursing - Care in context. Oxford: Blackwell Science.

6. Speziale, H., \& Carpenter, D. (2007). Qualitative research in nursing: Advancing the humanistic imperative (4th ed.). Philadelphia: Lippincott Williams \& Wilkins.

7. American Society of Clinical Oncology. (2012). Depression and anxiety. Retrieved from http://www.cancer.net./ 
8. Markides, M. (2011). The importance of good communication between patient and health professionals. Journal of Pediatric Hematology/Oncology, 33(2), S123-S125. http://www.ejoncologynursing.com/article/S1462-3889(14)00038-6/references

9. Legg, M. (2015). What is psychosocial care and how can nurses better provide it to adult oncology patients. Australian Journal of Advanced Nursing, 28(3), 61-67. https://www.highbeam.com/doc/1P3-2336176781.html

10. Vondrasek, J., \& Cody, J. (2012). Nurses key in helping new cancer patients overcome fear. Retrieved from http://msutoday.msu.edu/news/2012/nurses-key-in-helping-new-cancer-patients-overcome-fears/

11. Barkley, P. (2016). Building rapport with your patient: Positive case management outcomes. Retrieved from http://www.nahc.org/news/building-rapport-with-your-patient-positive-case-management-outcomes/

12. Bowen, M. (2012). The importance of the nurse and patient relationship. Retrieved from https://www.seniorhomes.com/w/theimportance-of-the-nurse-and-patient-relationship/

13. Tabatabaee, A., Tafreshi, M., Rassouli, M., Aledavood, S., AlaviMajd, H., \& Farahmand, S. (2016). Effect of therapeutic touch in patients with cancer: A literature review. Medical Archives: Journal of the Academy of Medical Sciences in Bosnia and Herzegovina, 70(2), 142-147. https://www.ncbi.nlm.nih.gov/pmc/articles/PMC4860206/pdf/MA-70-142.pdf

14. Ness, 2012

15. Joshua, A., Cotroneo, A., \& Clarke, S. (2005). Humor and oncology. Journal of Clinical Oncology, 23(3), 645-648. http://ascopubs.org/doi/full/10.1200/jco.2005.09.064

16. International Association for the Study of Lung Cancer. (2010, September 29). Lung cancer with optimistic attitudes have longer survival, study finds. Retrieved from https://www.sciencedaily.com/releases/2010/03/100303131656.htm

17. Larsson, Hedelin and Athlin (2007

18. Sherman, D., Rosedale, M., \& Haber, J. (2012). Reclaiming life on one's own terms: A grounded theory study of the process of breast cancer survivorship. Oncology Nursing Forum, 39(3), E258-E268. http://store.ons.org/article/find?

19. Weaver, A. (2001). Cancer patients and caregivers benefit from religious faith. Retrieved from http://www.ourjourneyofhope.com/general-resources/cancer-patients-and-caregivers-benefit-from-religious-faith/

20. Abendroth, M., \& Flannery, J. (2006). Predicting the risk of compassion fatigue. Journal of Hospice and Palliative Nursing, 8(6), 346-355. http://www.compassionstrengths.com/uploads/Compassion_fatigue_nursing.pdf

21. Meier, J., \& Beresford, L. (2006). Preventing burnout. Journal of Palliative Medicine, 9(5), 1045-1048.

22. Rokach, A. (2005). Caring for those who care for the dying: coping with the demands on palliative care workers. Palliative and Supportive Care, 3(4), 325-332. https://www.cambridge.org/core/journals/palliative-and-supportive-care/article/caring-for-thosewho-care-for-the-dying-coping-with-the-demands-on-palliative-care-workers/170C5B153F1F5FFC7DA0A9F664A2082

23. Vachon, M. (1998). Caring for the caregiver in oncology and palliative care. Seminars in Oncology Nursing, 14(2), $152-157$. https://www.researchgate.net/publication/13703012_Caring_for_the_caregiver_in_oncology_and_palliative_care

24. Wakefield, A. (2000). Nurses' responses to death and dying: a need for relentless self-care. International Journal of Palliative Nursing, 6(5), 245-251. http://www.magonlinelibrary.com/doi/abs/10.12968/ijpn.2000.6.5.8926?url_ver=Z39.882003\&rfr_id=ori\%3Arid\%3Acrossref.org\&rfr_dat=cr_pub\%3Dpubmed\&

25. Western Governors University. (2013, July 6). Tips for nurses: How to have patience with patients. Retrieved from http://www.wisecareers.com/articles/nursing/tips-nurses-how-have-patience-patients

26. Heacock, S. (2012, September 29). 5 'must-haves' for a successful nursing career. Retrieved from http://www.nursetogether.com/5-must-haves-successful-nursing-career

27. Freire, M., Sawada, N., de Franca, I., da Costa, S., \& Oliveira, C. (2014). Health-related quality of life among patients with advanced cancer: An integrative review. Retrieved from http://www.scielo.br/pdf/reeusp/v48n2/0080-6234-reeusp-48-02-357.pdf. 